\title{
BCR/ABL1 Fusion Gene p210
}

National Cancer Institute

\section{Source}

National Cancer Institute. BCR/ABL1 Fusion Gene p210. NCI Thesaurus. Code C99306.

A fusion gene that results from a chromosomal translocation $t(9 ; 22)(q 34 ; q 11)$ that fuses the 5 ' part of the BCR gene between exons 12 and 16 to the 5 ' side of exon 2 of the $A B L 1$ gene. This rearrangement is associated with chronic myelogenous leukemia, acute lymphoblastic leukemia and acute myeloid leukemia. 